\title{
Penilaian Siswa SMK Yuppentek 3 Balaraja Tangerang Berbasis Web Sebagai Media Informasi
}

\author{
Wahyu Hidayat $^{1}$, Dede Cahyadi ${ }^{2}$, Deny Arbiyanto ${ }^{* 3}$ \\ ${ }^{1,3}$ Program Studi Sistem Informasi Fakultas Sains and Teknologi Universitas Raharja, ${ }^{2}$ Program \\ Studi Komputerisasi Akuntansi Fakultas Sains and Teknologi Universitas Raharja \\ E-mail: ${ }^{1}$ wahyu@ raharja.info, ${ }^{2}$ dede.cahyadi@ raharja.info,,${ }^{* 3}$ deny.arbiyanto@ raharja.info
}

\begin{abstract}
Abstrak
Informasi teknologi begitu cepat meningkat seperti komputer banyak digunakan masyarakat sehari-hari, diantaranya dalam pendidikan, komputer sangat dibutuhkan. Dengan peningkatan informasi yang cepat tersebut maka Media informasi sangat penting karena salah satu alat untuk mengumpulkan dan menyusun kembali sebuah informasi sehingga menjadi bahan yang bermanfaat bagi penerima informasi. Banyak guru memiliki kesulitan dalam memberikan nilai karena masih berbentuk manual sehingga memerlukan waktu lama dalam memberikan nilai dengan menggunakan Microsoft Excel, dengan demikian pembuatan sistem penilaian sangat diperlukan sebagai media informasi bagi siswa dan guru. Agar para guru dapat lebih mudah dalam menginput nilai dan siswa dapat secara langsung melihat nilainya. Sistem yang akan dirancang dalam pembuat fasilitas penilaian ini menggunakan web, UML (Unified Modeling Language), PHP, MYSQL dan Black Box testing dengan metode analisa SWOT (Strenghts Weakness Opportunities Threats).
\end{abstract}

Kata Kunci-Web, Microsoft Excel, Informasi

\begin{abstract}
Information technology is increasing so fast that computers are widely used in everyday society, including in education, computers are needed. With the rapid increase in information, information media is very important because it is one of the tools to collect and rearrange information so that it becomes useful material for recipients of information. Many teachers have difficulty in giving grades because they are still in manual form so it takes a long time to provide grades using Microsoft Excel, thus making an assessment system is needed as a medium of information for students and teachers. So that teachers can more easily input grades and students can immediately see the value. The system to be designed in this assessment facility maker uses the web, UML (Unified Modeling Language), PHP, MYSQL and Black Box testing with the SWOT analysis method (Strenghts Weakness Opportunities Threats).
\end{abstract}

Keywords-Web, Microsoft Excel, information 


\section{PENDAHULUAN}

Media informasi saat ini memiliki banyak jenis yang lebih mudah diakses dengan menggunakan jaringan internet secara online, seperti google, sosial media, blog, youtube dan lain-lain. Nilai berarti keistimewaandan Harkat [4] yang dimiliki siswa sebagai Konsep Dasar Penilaian sedangkan guru merupakan seseorang yang memiliki kemampuan dan pengalaman dalam memberikan materi [5] kepada siswa yang sedang belajar.[6]

SMK Yuppentek 3 Kabupaten Tangerang adalah salah satu SMK yang memiliki teknologi yang canggih, sudah seharusnya menggunakan cara-cara yang lebih modern seperti siswa dapat melihat nilai dan guru dapat menginput nilai dengan lebih mudah dan cepat melalui web sistem, Sistem memiliki unsur yang disebut dengan subsistem. Subsistem berinteraksi melalui komunikasi yang relevan [1], sehingga up to date lebih diutamakan. Sebelum menggunakan sistem penilain menggunakan teknologi, para guru menginput nilai dengan microsoft excel sehingga memerlukan waktu yang lama dalam menginput data nilai siswa, siswa pun tidak dapat melihat nilai tersebut melalui web hanya melalui guru tersebut.

\subsection{Literature Review}

1. Aini, Q.,dkk. pada Jurnal INFORMATIKA UPGRIS (2018) dengan berjudul "Penerapan menggunakan Gamifikasi Sistem Informasi pada Penilaian Ujian Mahasiswa yang dilakukan untuk lebih Meningkatkan Kinerja Dosen "Penerapan gamifikasi PEN+ sendiri menggunakan metode pengumpulan data, analisa sistem, perancangan dan pengembangan sistem. [9]

2. Rahardja, U., dkk. pada Jurnal Ilmiah SISFOTENIKA (2017) melakukan penelitian dengan menggunakan Dashboard, pada saat ini begitu banyak media yang dapat digunakan untuk menyampaikan informasi salah satunya adalah menggunakan Dashboard. Dashboard yaitu Sebuah tampilan yang digunakan untuk menyampaikan informasi secara real time dan dinamis. dengan mengoptimalisasikan dashboard pada sistem penilian dapat mempermudah mahasiswa dalam megakses informasi nilai tertinggi dan nilai terendah sehingga menjadi lebih efektif dan efesien.[10]

3. Penelitian yang dilakukan oleh Tiara, K., dkk. pada Jurnal ICIT (2017) memanfaatkan sistem DID (Dream Innovation Day) sebagai media pendukung penilaian Raharja Career yang terdapat pada PO (Penilaian Objektif) Sidang berbasis iMe (iLearning Media) yang dapat diakses secara online metode yang digunakan adalah mind mapping dan analisa SWOT[11]

4. Maimunah., dkk meakukan penelitian dalam jurnal CERITA (2017) tentang fasilitas sistem permohonan cuti karyawan berbasis aplikasi SMS Gateway. Sistem ini dibangun menggunakan software Gammu dengan menggunakan bahasa pemrograman PHP sebagai awal peng-inputan data pengajuan yang disimpan pada database MySQL, kemudian dihubungkan dengan konsep client-server yang sesuai dalam Osi layer, serta output hasil memanfaatkan fasilitas sms gateway, sehingga proses pelayanan, pengajuan, pengecekan dan pengambilan keputusan hak cuti pegawai dapat dilakukan secara sistematis Selain itu,proses pengajuan cuti dapat menjadi lebih transparan[12]

\section{METODE PENELITIAN}

Pengumpulan data yang didapat secara langsung pada lokasi penelitian (Observasi). Kemudian melakukan wawancara kepada stakeholder dan Studi Pustaka tentang data yang berhubungan dengan penelitian lewat buku maupun literatur lainnya.

Selanjutnya data yang telah diperoleh pada saat melakukan observasi dan wawancara dikumpulkan serta dianalisis menggunakan metode analisa SWOT (Strenghts yaitu kekuatan, Weakness yakni kelemahan, Opportunities kesempatan atau peluang, dan Threats Ancaman). 
[2]. Untuk menganalisis prosedur yang berjalan menggunakan UML (Unified Modelling Language) merupakan penulisan cetak biru pada perangkat lunak. [7] melalui tahap: use case diagram, activity diagram, sequence diagram dan class diagram.

Bahasa pemrograman menggunakan PHP, untuk menjalankan PHP harus menggunakan web server [6] XAMPP merupakan perangkat lunak termasuk yang bebas, yang kotributif di sistem operasi, merupakan kumpulan dari bermacam program.[8]

Sedangkn basis data menggunakan MySQL, perangkat lunak pendukung menggunakan Sublime Text dan CSS (Cascading Style Sheet).

Metode pengujian merupakan tahap akhir sebelum sistem yang telah dibuat diimplementasikan. Metode pengujian ini menggunakan black box testing, yaitu tes yang diperlukan untuk mencari fungsi perangkat lunak apakah sudah berfungsi sesuai kebutuhan, sehingga dapat memudahkan user untuk mengetahui letak kesalahannya.

\section{HASIL DAN PEMBAHASAN}

\subsection{Use Case Diagram}

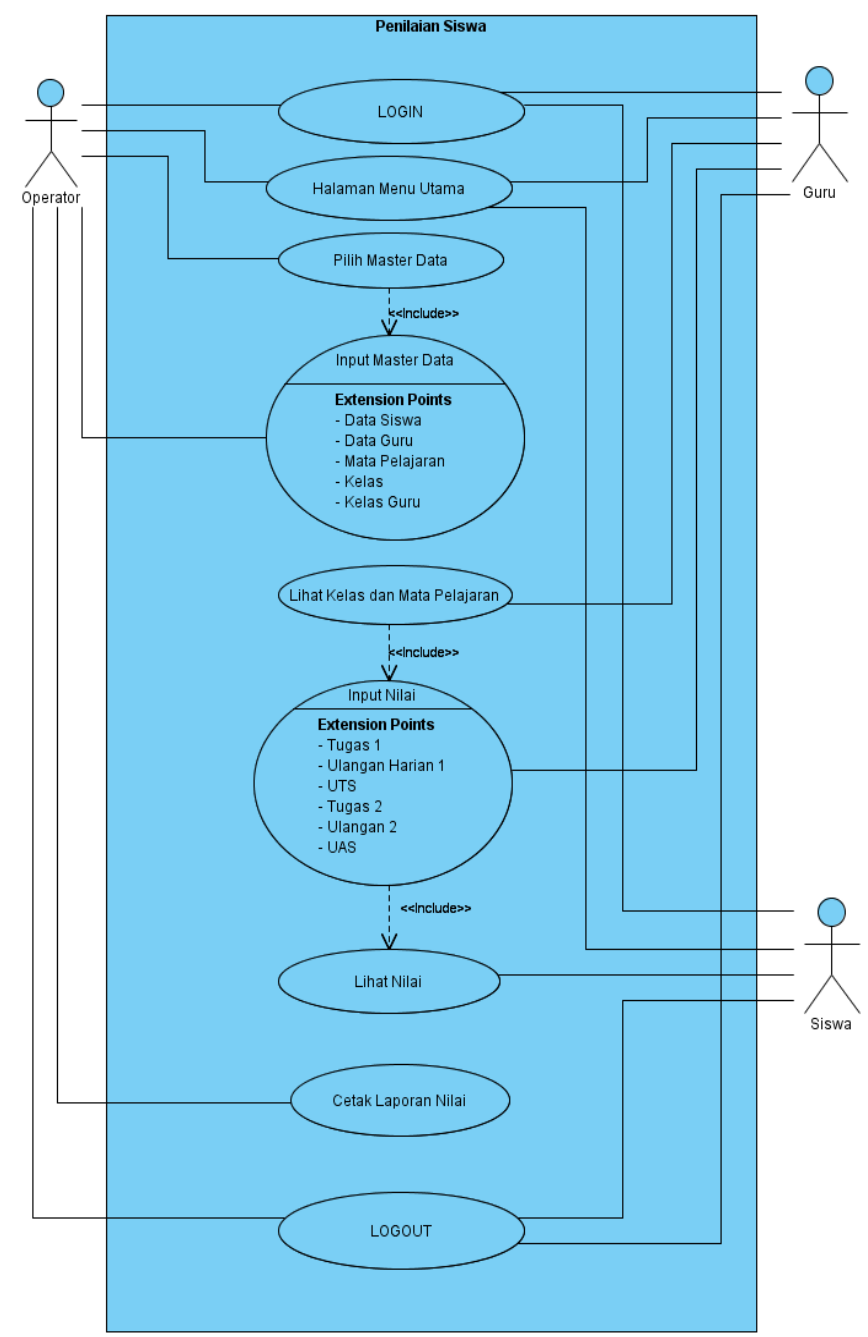

Gambar 1. Penilaian Siswa

a. 1 memproses seluruh penilaian.

b. 3 penilaian.

c. 9 login dan logout. 
3.2. Activity Diagram

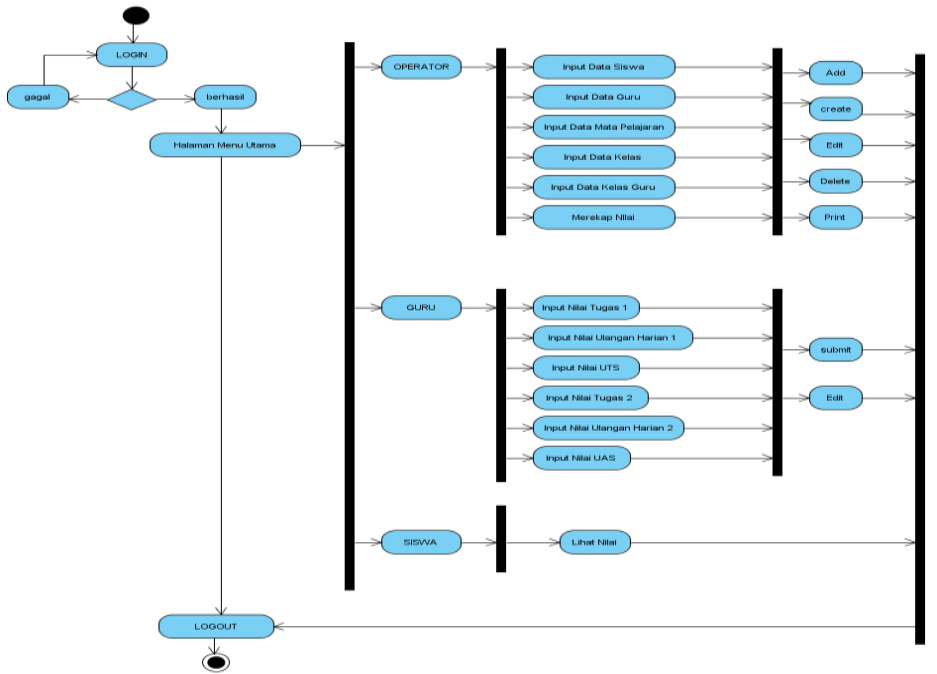

Gambar 2. Activity Diagram

1. 1 Intial nodes objek.

2. 28 action, state.

3. 1 (satu) final node, diakhiri.

\subsection{Sequence Diagram}

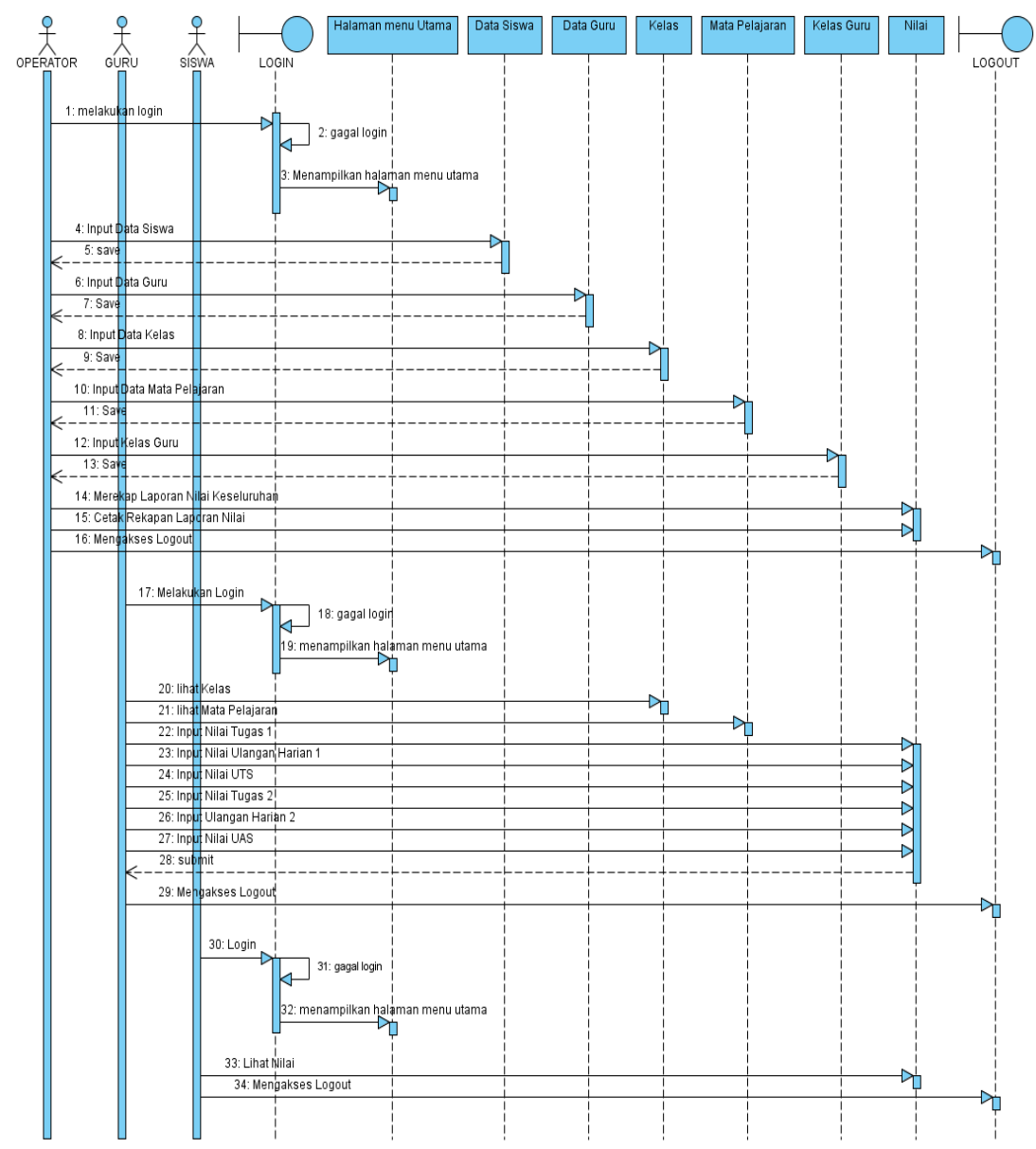

Gambar 3. Sequence Diagram 
1. 9 line life antarmuka berinteraksi.

2. 3 actor operator, guru, dan siswa.

3. 34 message informasi tentang kegiatan saat terjadi.

\subsection{Class Diagram}

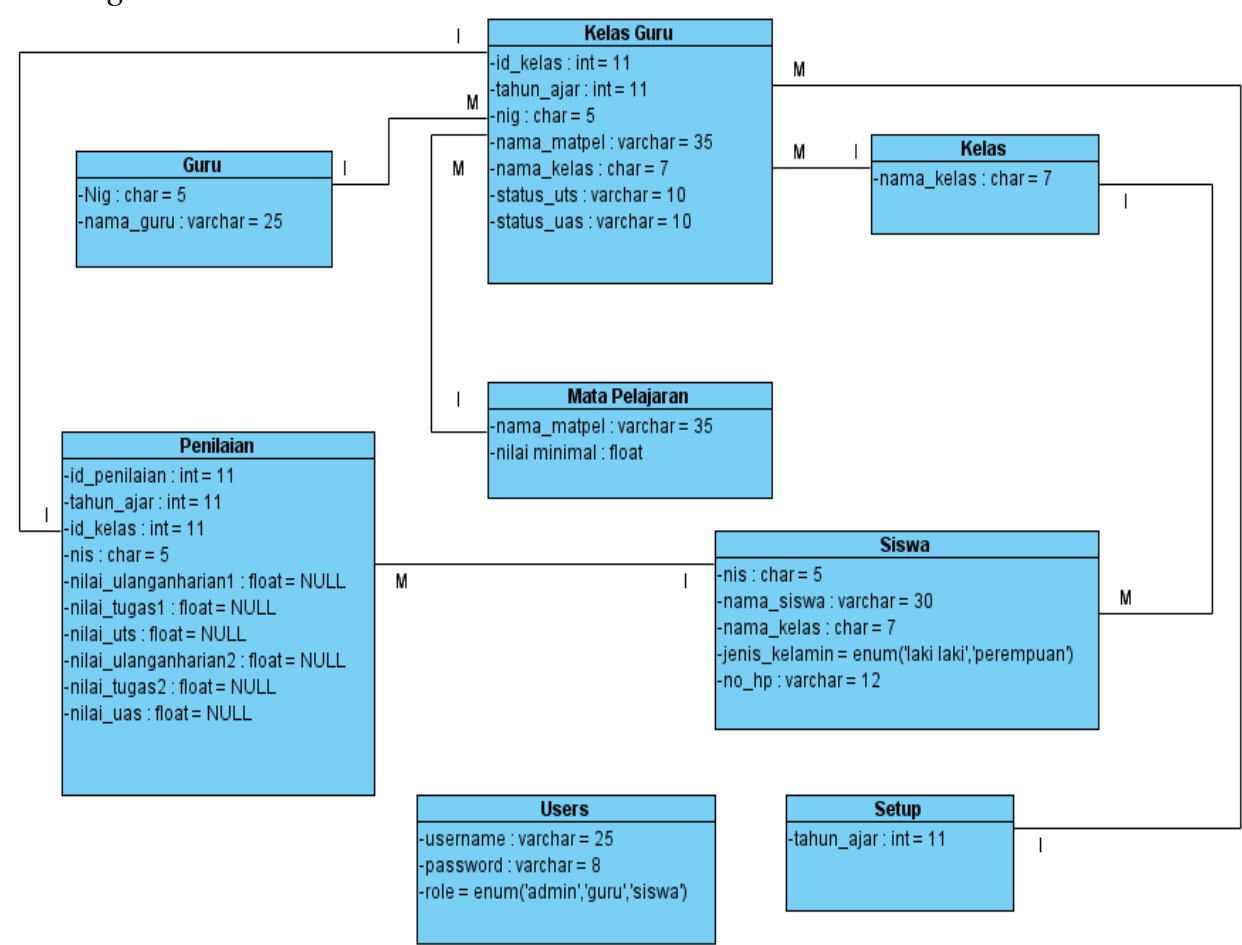

Gambar 4. Class Diagram

Keterangan :

1. 8 class

2. 7 association.

\subsection{Implementasi Sistem}

\subsubsection{Menu Login Pada Operator/Guru/Siswa}

SMK Yuppentek 3 Balaraja

Tangerang

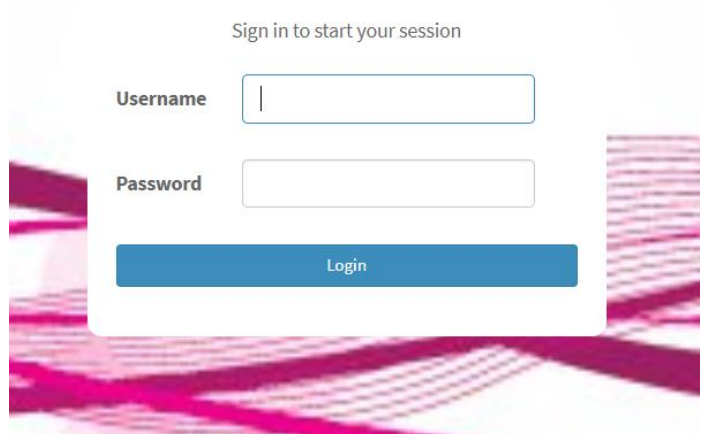

Gambar 5. Tampilan Menu Login 


\subsubsection{Menu Home Pada Operator}

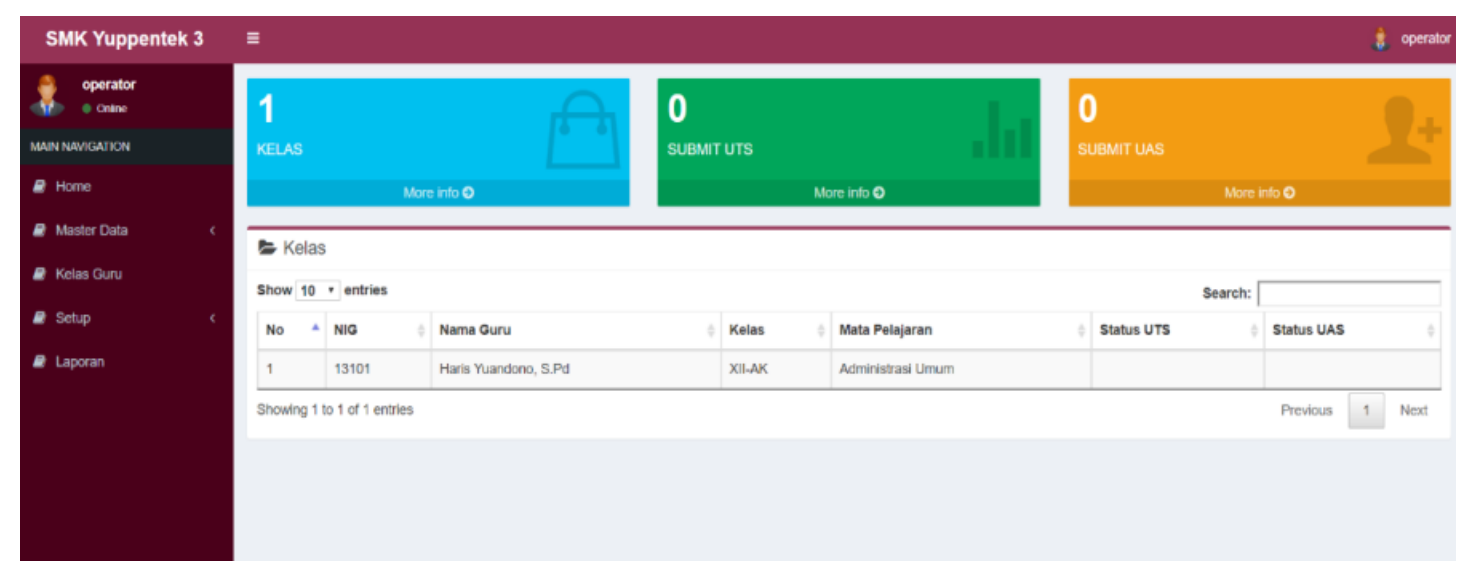

Gambar 6. Menu Home

\subsubsection{Menu Pada Master Data Siswa}

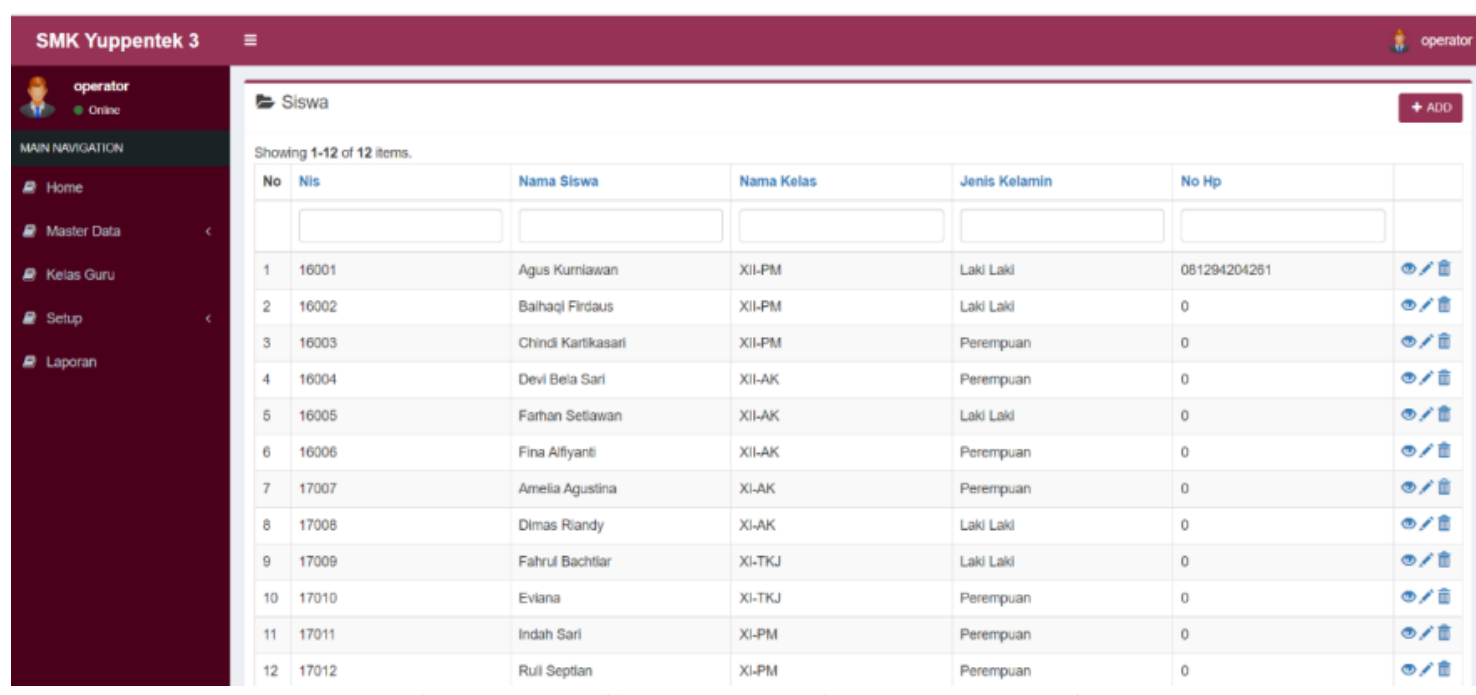

Gambar 7. Tampilan Menu Pada Master Data Siswa

\subsubsection{Halaman Pada Create Data Siswa}

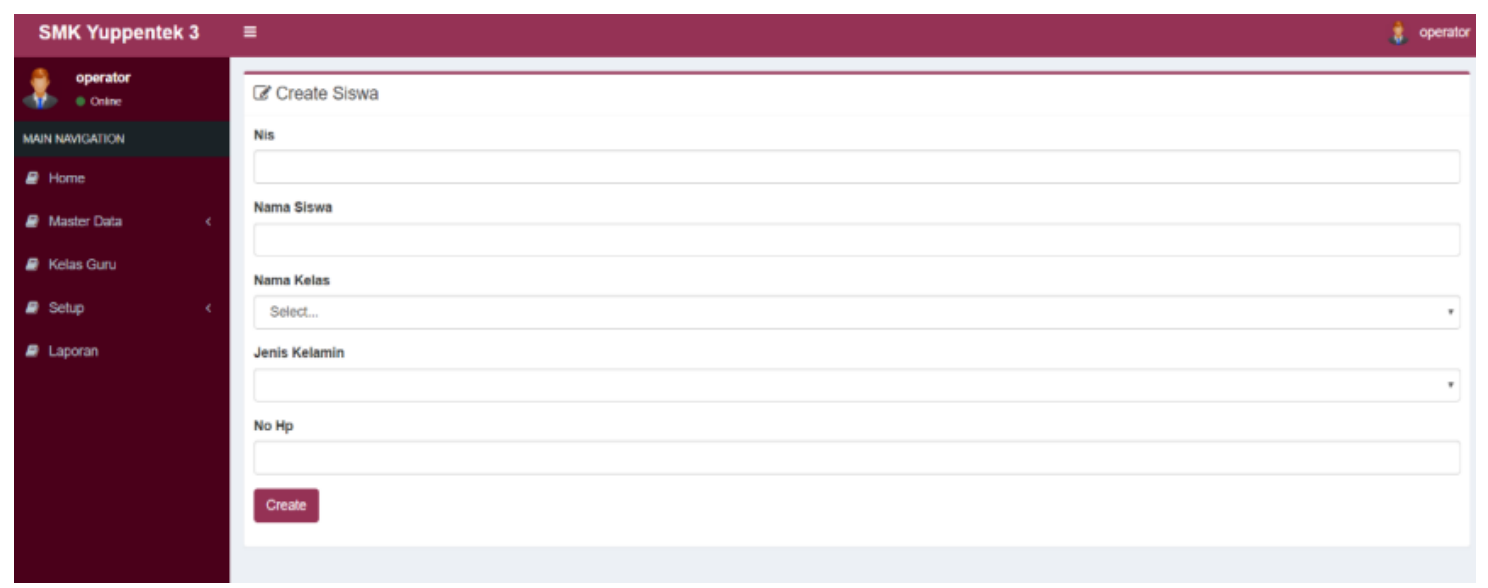

Gambar 8. Tampilan Halaman Pada Create Data Siswa 


\subsubsection{Menu Pada Master Data Guru}

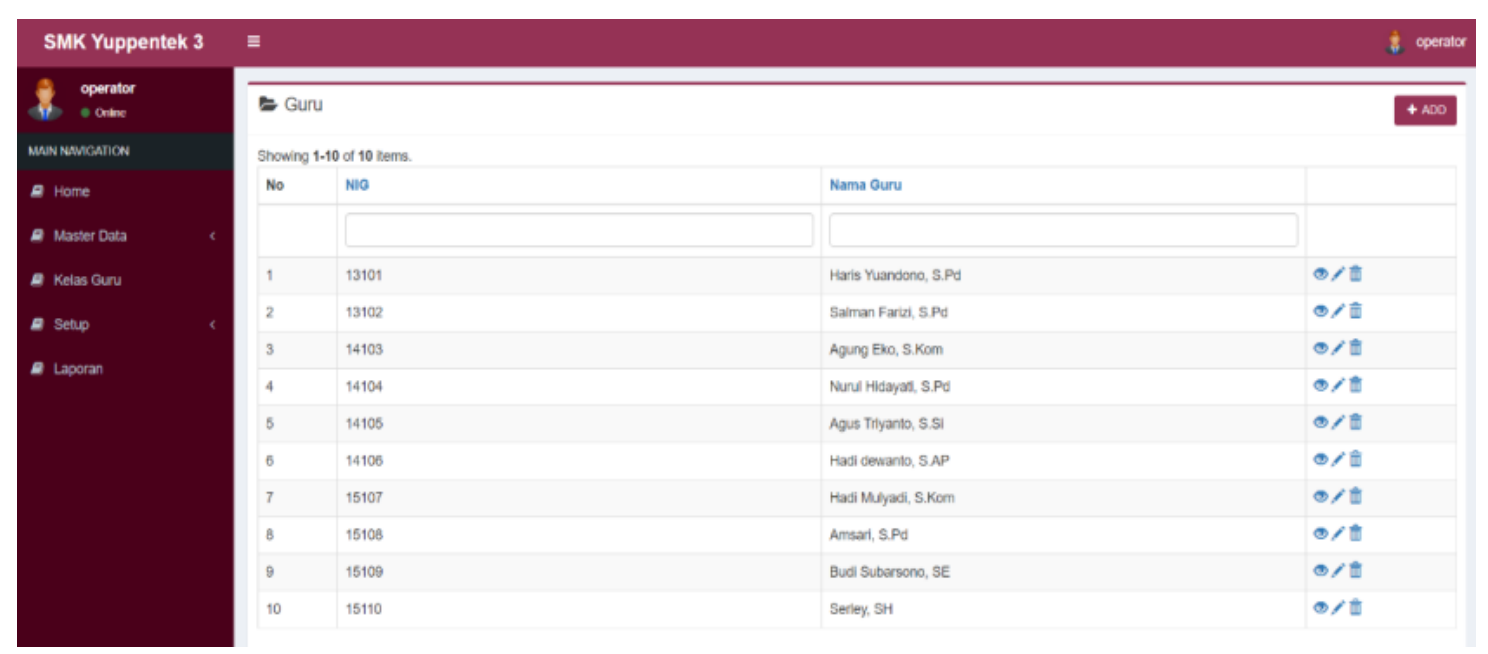

Gambar 9. Tampilan Menu Pada Master Data Guru

\subsubsection{Halaman Pada Create Data Guru}
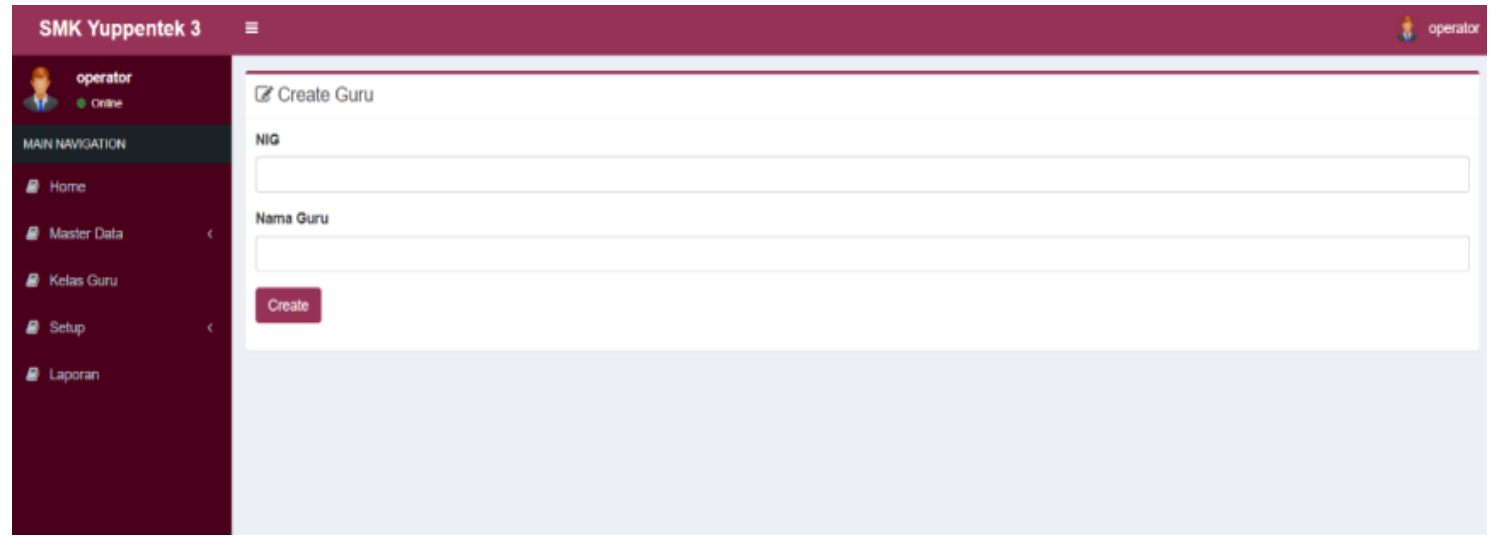

Gambar 10. Tampilan Halaman Pada Create Data Guru

\subsubsection{Halaman Pada Create Data Kelas}

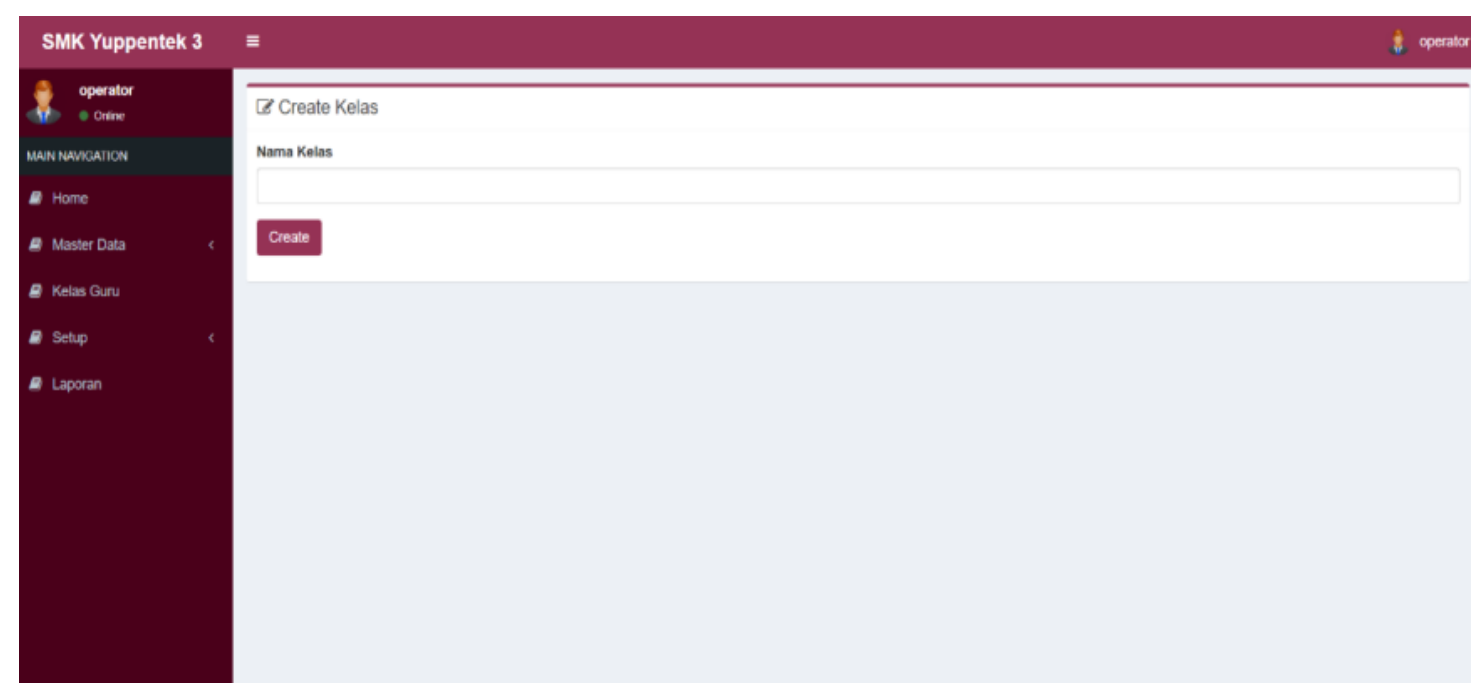

Gambar 11. Tampilan Halaman Pada Create Data Kelas 


\subsubsection{Menu Pada Master Data Mata Pelajaran}

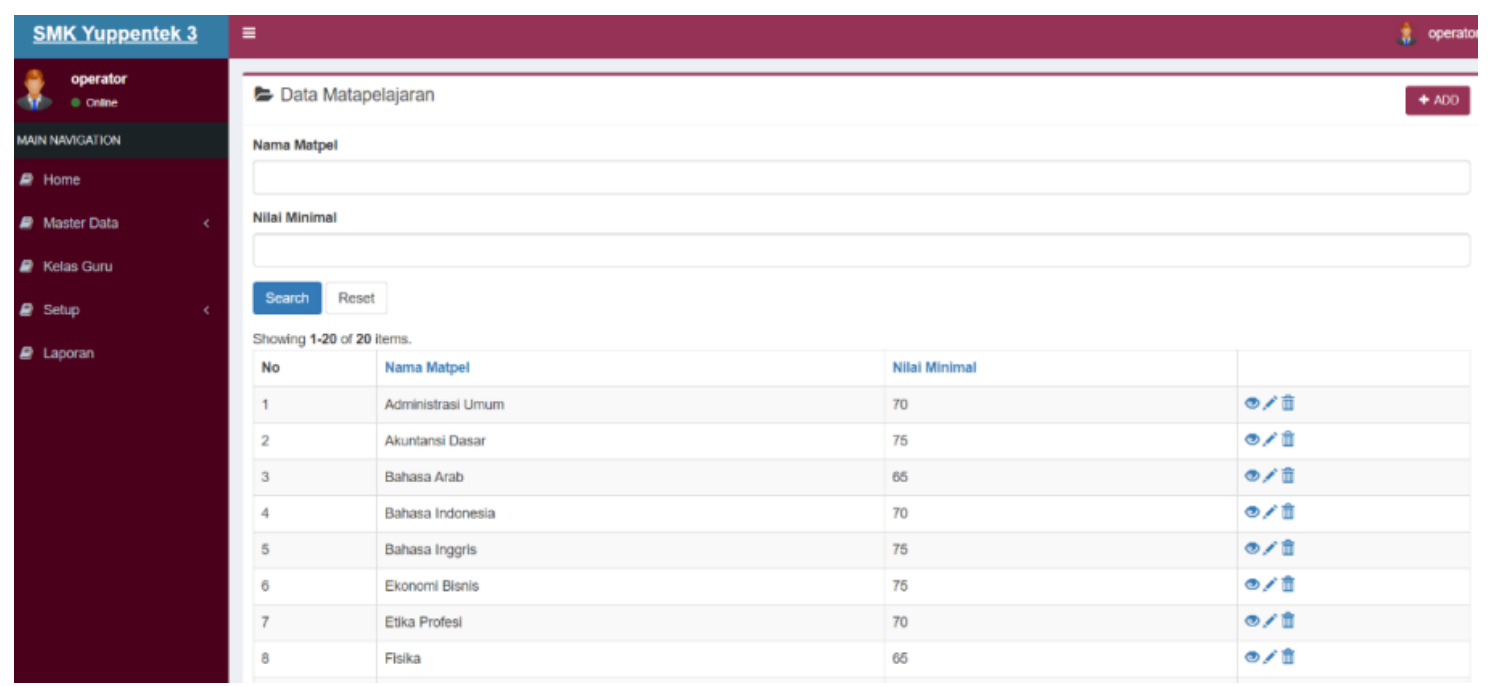

Gambar 12. Tampilan Menu Pada master Data Mata Pelajaran

\subsubsection{Halaman Pada Create Data Mata pelajaran}

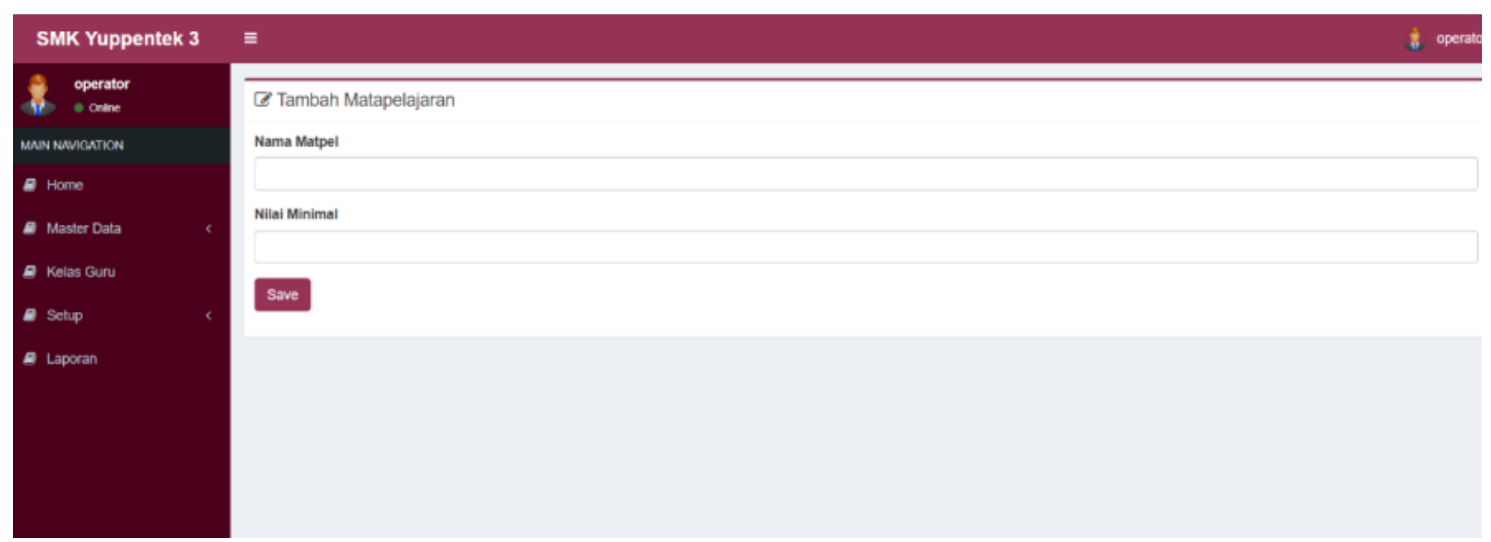

Gambar 13. Tampilan Halaman Pada Create Data Mata Pelajaran

\subsubsection{Halaman Pada Submit Nilai UTS}

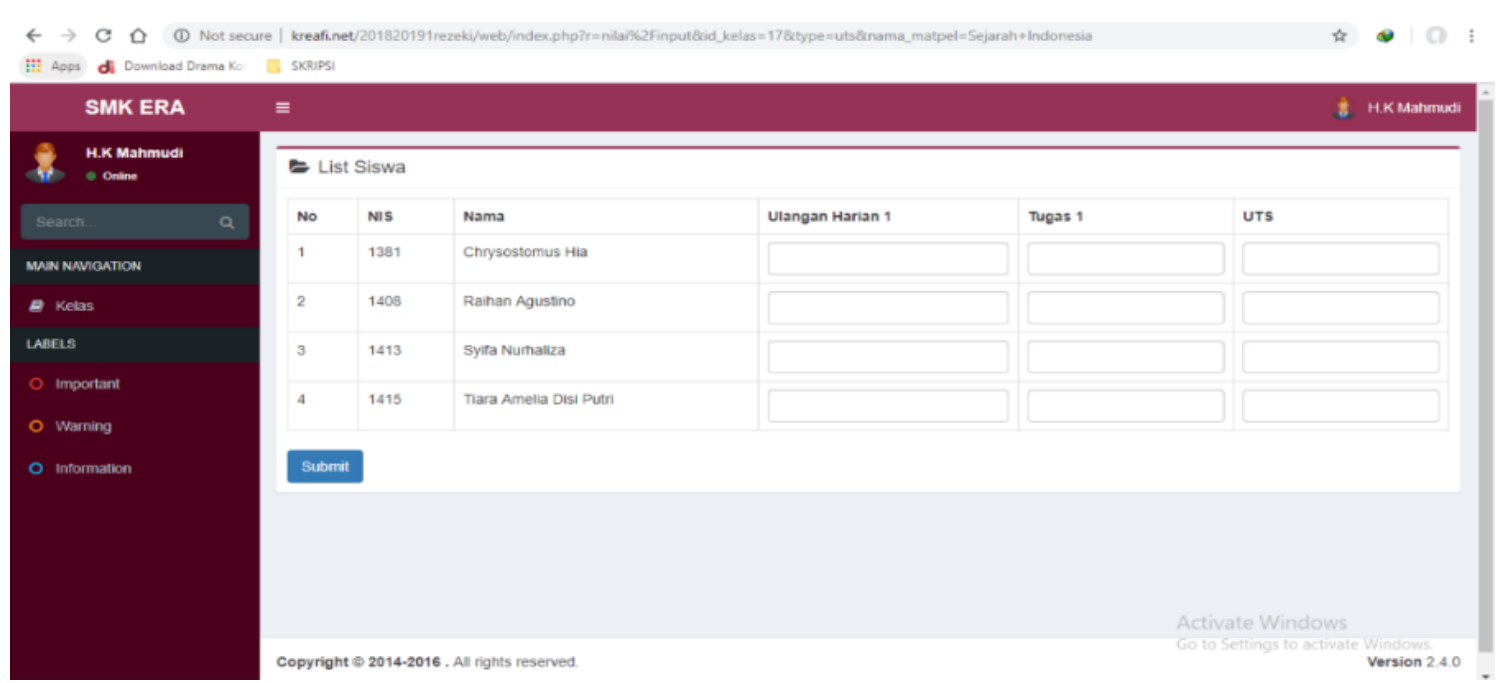

Gambar 14. Tampilan Pada Halaman Submit Nilai UTS 


\section{KESIMPULAN}

Media informasi merupakan salah satu alat dalam mengumpulkan data informasi yang telah diolah sehingga menjadi bahan yang bermanfaat dan mudah diakses, dengan menggunakan jaringan internet, informasi bisa didapatkan secara online, untuk menjangkau informasi tersebut dapat menggunakan peralatan teknologi komputer dan smartphone. Yang dihadapi saat menggunakan sistem penilaian siswa yang saat ini sedang berjalan pada SMK Yuppentek 3 Balaraja Tangerang sangat lambat menggunakannya karena masih menggunakan manual yang dimana penilaian tersebut harus diinput satu persatu menggunakan Ms. Excel sehingga akan rumit karena menggunakan rumus. Dengan adanya sistem penilaian berbasis web ini maka para guru dapat memproses nilai siswa menjadi lebih mudah dan lebih cepat.

\section{SARAN}

Agar penggunaan sistem lebih optimal disarankan untuk melakukan pengarahan dan pelatihan kepada para guru dan siswa SMK Yuppentek 3 Balaraja Tangerang.

\section{DAFTAR PUSTAKA}

[1] Iswandy, E. (2015). "Sistem Penunjang Keputusan Untuk Menentukan Penerimaan Dana Santunan Sosial Anak Nagari Dan Penyalurannya Bagi Mahasiswa Dan Pelajar Kurang Mampu Di Kenagarian Barung-Barung Balantai Timur”. Jurnal TeknoIf.

[2] S. D., Rahayu, D.R., Lucitasari dan S. Sutrisno (2018). PENENTUAN STRATEGI BERSAING BERDASARKAN SIMULASI SISTEM DINAMIS . JURNAL OPSIISSN 1693-2102, 11(1), 58-64. (Studi Kasus di Industri Kecil Intan Rahmadhani Yogyakarta)

[3] Sudarsih, S. (2017). NILAI KESEDERHANAAN DAN NILAI KEDISIPLINAN SEBAGAI LANDASAN KEHIDUPAN MASYARAKAT JEPANG. KIRYOKU, 1(3), 48-53.

[4] K. Sudarsana, (2017). "Optimalisasi Pemahaman Ajaran Tri Hita Karana Dalam Meningkatkan Karakter Siswa Sekolah Dasar (Perspektif Psikologi Pendidikan)". Prosiding di Senada 2, Hal 250-256.

[5] Z. V. K. Kastina, (2016). 2013 Di SMA Negeri 2 Pekanbaru. Implementasi Sistem Penilaian Dalam Kurikulum. Jurnal Online Mahasiswa (JOM) Pada Bidang Ilmu Sosial dan Ilmu Politik, 4(1), 1-15.

[6] N.,Monica, S., Sarkum, \& I. Purnama, (2018). IT JOURNAL RESEARCH AND DEVELOPMENT “Aplikasi Data Mahasiswa Berbasis Android: Studi Pada Sekolah Tinggi Ilmu Ekonomi Labuhanbatu”. 3(1), 43-53.

[7] M. F. Asnawi, (2018). Jurnal Penelitian dan Pengabdian kepada Masyarakat UNSIQ. Aplikasi Konfigurasi Mikrotik Sebagai Manajemen Bandwidth Dan Internet Gateway Berbasis Web.

[8] S. M., Widodo, \& J. Sutopo, (2018). Metode Customer Satisfaction Index (CSI) Untuk Mengetahui Pola Kepuasan Pelanggan Pada E-Commerce Model Business to Customer. Jurnal Informatika Upgris. 
[9] Aini, Q., Rahardja, U., Moeins, A., \& Apriani, D. M. (2018). Penerapan Gamifikasi pada Sistem Informasi Penilaian Ujian Mahasiswa Untuk Meningkatkan Kinerja Dosen. Jurnal Informatika Upgris, 4(1).

[10] Rahardja, U., Aini, Q., \& Enay, N. (2017). Optimalisasi Dashboard pada Sistem Penilaian Sebagai Media Informasi di Perguruan Tinggi. Sisfotenika, 7(2), 167-176.

[11] Tiara, K., Apriani, D., \& Al Munawaroh, J. (2017). Optimalisasi Dream Innovation Day Sebagai Media Penunjang Penilaian Raharja Career. Innovative Creative and Information Technology, 3(1), 74-90.

[12] Maimunah, M., Singgih, S., \& Supriyadi, A. (2017). Rancang Bangun Sistem SMS Gateway sebagai Fasilitas Permohonan Cuti Karyawan. Journal Cerita, 3(1), 36-48. 